occurred after withdrawal of the nifedipine. In each case, significant improvement occurred almost immediately and recovery within one week was usual. The temporal association alone is insufficient to prove a causal relationship between nifedipine and depression, but in view of the widespread use of nifedipine, particularly by the elderly, clinicians should be alert to the possibility of depression occurring as an adverse effect.

ECCLESTON, D. \& COLE, A. J. (1990) Calcium-channel blockade and depressive illness. British Journal of Psychiatry, 156, 889-891.

Hullett, F. J., Potkin, S. G., Levy, A. B., et al (1988) Depression associated with nifedipine-induced calcium channel blockade. American Journal of Psychiatry. 145, 1277-1280.

R. W. LYNDON GORDON JOHNSON

Mood Disorders Unit

G. McKeOUGH

Northside Clinic

Greenwich Road

Greenwich NSW 2065

Australia

\section{Bizarre delusion and post-hemiplegic hemidystonia}

SIR: Owens (Journal, May 1990, 156, 620-634) recently underlined the importance of being familiar with the manifold presentations of dystonia, as they are a potential psychiatric pitfall. In the absence of clearly identifiable clinical causes, dystonic symptoms are often considered psychogenic (Pinto de Azevedo, Journal, March 1991, 158, 436). However, we are unaware of any reports of psychiatric changes in patients with symptomatic dystonia. To illustrate the need for a more systematic psychiatric investigation, we describe a case of a post-hemiplegic hemidystonia associated with bizarre delusions, which is the first report of an organic delusional disorder in this rare neurological disturbance.

Case report. The patient was a 65 -year-old man, who had been struck by a car three years earlier, leading to a traumatic hemorrhage in the left basal ganglia with a right hemiplegia and an organic personality syndrome. Five months later he developed a bizarre delusion: he said artif- cial tubes had been implanted into his body, beginning under his tongue, running down his chest and stomach to his back, and forming two intestinal outlets. Furthermore, a metal stabilisation system had been extracted from his left leg. One year later, slow involuntary right-rotating muscle contractions of his right hand appeared, later extending to his right arm, shoulder, neck, mouth, tongue, and facial muscles. A computerised tomography scan showed a hypodense zone $11 \mathrm{~mm} \times 3 \mathrm{~mm}$ in size, beginning in the left medio-dorsal part of the lentiform nucleus and extending to the fronto-parietal white matter.

Pettigrew \& Jankovic (1985) provided evidence that contra-lateral basal ganglia damage and a history of hemiparesis due to head trauma and cerebral haemorrhage can be found in a number of hemidystonic patients. A considerable delay of months or years before the onset of dystonic symptoms and a subsequent progression of symptoms has also been reported (Grimes et al, 1982). A disconnection between the striatum and the thalamus with relative preservation of the cortico-spinal pathway is discussed as the underlying pathomechanism (Dooling \& Adams, 1975). Although in our case the possible role of an intermittent unsuccessful neuroleptic therapy in the triggering of the dystonic symptoms (Myslobodsky et al, 1984) remains obscure, the topography of the brain damage and the patient's history support a diagnosis of post-traumatic hemidystonia.

Dooling, E. C. \& ADAMs, R. D. (1975) The pathological anatomy of posthemiplegic athetosis. Brain. 98, 29-48.

Grimes, J. D., Hassan, M. N., Quarrington, A. M., et al (1982) Delayed-onset posthemiplegic dystonia: CT demonstration of basal ganglia pathology. Neurology, 32, 1033-1035.

Mrslobodsky, M. S., Holden, T. \& SANDLeR, R. (1984) Asymmetry of abnormal involuntary movements: a prevalence study. Biological Psychiatry, 19, 623-628.

Pettigrew, L. C. \& JANkovic, J. (1985) Hemidystonia: a report of 22 patients and a review of the literature. Journal of Neurology. Neurosurgery and Psychiatry, 48, 650-657.

Max Planck Institute of Psychiatry

M. B. KELLNER

F. STRIAN

Clinical Institute

Kraepelinstrasse 2-10

D-8000 Munich 40, Germany

\title{
CORRIGENDUM
}

Journal, August 1991, 159, 294. The references to

Szabadi \& Cashman should read Burrell et al. 